\author{
JULIAN MEZA
}

\title{
Modernos y postmodernos: novedad y repetición
}

S. OLO quiero exponer brevemente algunas consideraciones $\checkmark$ sobre el tema de la modernidad y la postmodernidad.

1. Me pregunto, en primer término, si es pertinente hablar de postmodernidad en un país donde todavía se aspira a la modernidad.

2. Respondo a mi pregunta:

Aun cuando México no ha llegado a apoyar firmemente sus pies en el suelo de la modernidad o quizá precisamente por esto mismo, tal vez tenga algún sentido hablar aquí de postmodernidad.

3. Existe la opinión más o menos generalizada de que las sociedades modernas (incluídas las que no lo son del todo, como México) atraviesan una época de crisis* que, paradójicamente, se prolonga.

4. Esta crisis recibe diversas denominaciones.

Para los optimistas es una crisis coyuntural (fundamentalmente económica) y, por lo tanto, pasajera.

Para algunos marxistas es una crisis (también fundamentalmente económica) del sistema capitalista.

La crisis es sólo moral, a juicio de los moralistas.

Es crisis de la imaginación y de la capacidad creativa de los hombres, en opinión de críticos y estetas.

Con la crisis se asiste puntualmente al cumplimiento de las profecías, señalan los apocalípticos.

Es el principio del fin o el cumplimiento cabal de la decadencia de Occidente, según los catastrofistas.

* Momento decisivo en un asunto de importancia (Corominas). 
Es una crisis generalizada de valores, en opinión de algunos escritores, artistas y filósofos.

Es el fin de los tiempos modernos, dicen los postmodernos.

5. Llámese como se llame, parece haber consenso en la existencia y aun en la amplitud de la crisis.

6. No hay consenso en cambio en cuanto al momento en que se inicia.

Para unos la crisis se remonta a la época en que se inicia la "desvalorización de los valores supremos" consignada por Nietzsche.

Para otros, como Husserl, la crisis hunde sus raíces en el inicio de la Edad Moderna, con Galileo y Descartes; cuando se impone la unilateralidad de la ciencia europea que reduce el mundo a mero objeto de investigación técnica y matemática.

Para otros más es consecuencia de lo que Heidegger llamaba el hundimiento en "el olvido del ser".

7. Tampoco hay consenso en los remedios para aliviar la crisis, si es que los hay, pues tampoco se propone seriamente remedio alguno.

8. Hasta hace aproximadamente unos quince años las soluciones que repetidamente se solían proponer a la crisis eran con frecuencia:

La superación del capitalismo con el socialismo.

El desarrollo de los países llamados subdesarrollados.

El crecimiento económico.

El progreso material de las sociedades; $y$ en menor medida:

La vuelta a la naturaleza.

$O$ el refugio en las religiones orientales.

9. La mayoría de estas soluciones tenían su fundamento en las reiteradás claves de la modernidad:

Las ideologías del progreso, el desarrollo, el crecimiento, el bienestar material.

10. Además de los fracasos del progreso, de las dificultades del desarrollo, de los desequilibrios del crecimiento y del descrédito del socialismo, la degradación ecológica, el incremento de la población y la amenaza nuclear han hecho que, desde hace más o menos una década, sean cada vez más raros y aun extravagantes los que todavía creen en algunas de esas soluciones (sobre todo en los países más modernos, pues en los 
menos modernos la seducción de la repetición, que sigue siendo percibida ccmo novedad, no se ha esfumado del todo). 11. Desde entonces, todo Occidente, pero también el Este parecen sumergirse cada vez más en el pesimismo, la apatía, el desencanto, el nihilismo pasivo.

12. Ciertamente, ha habido reacciones en algunas sociedades que partieron al reencuentro con la esperanza. Polonia se movilizó ejemplarmente en busca de la solidaridad humana presente, pero su ejemplaridad aún no ha tenido porvenir.

13. Como una especie de desencuentro con el pesimismo y la apatía se abandonan los conceptos claves de la modernidad y se fragua la postmodernidad. Esta se autodefine (Vattimo, Lyotard) no como un intento por superar o ir más allá de la modernidad, sino como una voluntad por salirse de sus cauces, por desertar de las vías de acceso a un supuesto porvenir e intentar una especie de reencuentro genealógico con el pasado para reanudar el hilo de la tradición espiritual ética, estética, política y social de Occidente.

No se trata de preparar así algo nuevo y mejor, sino de hallar un efecto reparador en esa misma tradición espiritual.

14. Debido a la unilateralidad de los caminos que eligió en el pasado, Occidente malogró o dejó de explorar otros caminos; abandonó y olvidó otras posibilidades; dejó de escuchar llamados que, tal vez, aún puede escuchar.

15. ¿Es esta una propuesta postmoderna?

No lo sé. Es probable que no. Pero independientemente de cómo se le llame quizá no sea del todo impertinente.

16. Aun si no hemos concluido la modernidad y las propuestas postmodernas se consideran "neoconservadoras" (Habermas) no estará por demás explorar otros caminos, recordar otras posibilidades, escuchar otros llamados.

17. Seguramente nada de esto cambiará al mundo, ni servirá para conjurar la amenaza nuclear, pero tal vez sea la única manera de reanudar el vínculo con el pasado espiritual de Occidente, que ha sabido renacer cada vez que se ha visto moralmente amenazado y se ha convertido así en un legado permanente.

18. Concluyó:

Este legado cultural de Occidente no lo constituyen los gestos elementales de lo cotidiano que son el Disneylandia de la cultura, sino las grandes creaciones del espíritu, la vida en 
relación con el pensamiento que, más allá de las singularidades culturales y de las edades de Occidente, no concluyen, se detienen o se interrumpen en ninguno de sus poetas, fílósofos y novelistas, que desde Homero, Tales y Esquilo, pasando por Dante, Shakespeare, Descartes, Cervantes y Pascal, hasta Octavio Paz, Michel Foucault y Milan Kundera son contemporáneos de todos los hombres. 